1. FCPS (Pediatric Medicine) Senior Registrar Pediatric Medicine Nishtar Medical University Hospital, Multan.

2. FCPS (Pediatric Medicine)

Assistant Professor Pediatric

Medicine

Nishtar Medical University Hospital Multan

3. MBBS

Postgraduate Registrar Pediatrics Nishtar Medical University Hospita Multan.

4. FCPS (Pediatric Medicine) Assistant Professor Pediatrics Nishtar Medical University Hospital, Multan

5. FCPS (Pediatric Medicine) Assistant Professor Pediatrics Nishtar Medical University Hospital, Multan.

6. MBBS

Postgraduate Registrar Pediatrics Nishtar Medical University Hospital, Multan.

Correspondence Address: Dr. Rabia Saleem Safdar

Department of Pediatric Medicine Nishtar Medical University Hospital, Multan

dr_rabiasaleem@live.com

Article received on:

24/03/2020

Accepted for publication: 27/06/2020

\section{Frequency of sensorineural hearing loss in children with bacterial meningitis.}

Rabia Saleem Safdar ${ }^{1}, \mathrm{M}$ Faisal Mehar ${ }^{2}$, Madiha Naz ${ }^{3}$, Afsheen Asghar Khan ${ }^{4}$, Nusrat Buzdar ${ }^{5}$, Tooba Aleem 6

ABSTRACT... Objectives: To determine the frequency of sensorineural hearing loss (SNHL) in children with bacterial meningitis. Study Design: Cross Sectional study. Setting: Department of Paediatric Medicine Nishtar Hospital, Multan. Period: October 2019 to March 2020. Material \& Methods: The study was conducted after permission from ethical committee. A total of 151 patients admitted with bacterial meningitis were enrolled. Apart from the presenting complaints, necessary information like the age and gender were noted. Examination of the child was done to assess the condition of child. Brainstem evoked response audiometry (BERA) test was performed before discharge of the patient from the hospital. The outcome variable that is SNHL in bacterial meningitis assessed by BERA test was noted in a specifically designed Performa. Results: Out of total of 151 patients, males were 83 (55\%) while females 68 (45\%). Overall mean age was $11.85+6.12$ months. SNHL was found in $26(17.2 \%)$ children. There was no significant effect of age or gender on the frequencies of SNHL. Conclusion: SNHL is a frequently encountered complication in our population of children suffering with bacterial meningitis. SNHL should be sought early and promptly diagnosed in all the patients presenting with bacterial meningitis.

Key words: $\quad$ BERA Test, Bacterial Meningitis, Sensorineural Hearing Loss.

Article Citation: Safdar RS, Mehar MF, Naz M, Khan AA, Buzdar N, Aleem T. Frequency of sensorineural hearing loss in children with bacterial meningitis. Professional Med J 2020; 27(12):2729-2733.

https://doi.org/10.29309/TPMJ/2020.27.12.4672

\section{INTRODUCTION}

Meningitis is inflammation of the meninges, the tissue surrounding the brain and spinal cord. Cause of meningitis may very well be bacterial, viral or fungal. ${ }^{1}$ Bacterial accounts for $3 \%$ of total hospital admissions. Highest risk of bacterial meningitis (BM) is between the age of 6-12 months while about $95 \%$ of the cases present between 1 months to 5 years of age. Incidence of BM is associated with high rates of mortality as well as risk of chronic morbidities. The incidence of $\mathrm{BM}$ is higher among developing nations in comparison to developed ones. ${ }^{2,3}$

\section{Group B Streptococci and E.coli are the} commonest causative organisms involved among neonates having meningitis. Neisseria meningitides, Streptococcus pneumoniae and Hemophilus influenza type $b$ are some of the most common orgnasims involved in meningitis beyond neonatal age group. ${ }^{4,5}$ Clinically, child presents having fever, inappropriate feeding, irritability, lethargy, headache as well as signs of meningeal irritation and bulging fontanella.,6 Diagnosis is reached with the help of clinical evaluation and cerebrospinal fluid (CSF) examination (raised pressure, turbid or clear, decreased serum glucose level $<40 \mathrm{mg} / \mathrm{dl}$, increased proteins usually $>80 \mathrm{mg} / \mathrm{dl}$, pleocytosis cells $>5 /$ $\mathrm{mm}^{3}$ usually $100-10,000 / \mathrm{mm}^{3}$ predominantly neutrophils. ${ }^{7}$ Commonly found consequences of meningitis include sensorineural hearing loss (SNHL), seizures, hydrocephalus, permanent neurological deficits, coma, or death. ${ }^{8,9}$ The commonest long term complication of meningitis is $\mathrm{SNHL}$ with overall rate of permanent deafness of $10 \%{ }^{10,11}$ This appear to develop in the early course of disease, more in pneumococcal meningitis Behavior problems are seen more among children having hearing loss while the 
level of behavioral problems is noted to be highest in children having hearing loss along with least developed language capabilities. It is really important to find out any degree of hearing loss as normal hearing is vital for usual development of speech as well as language. ${ }^{11}$ All children need to undergo audiological assessment after recovery from infection. Auditory brain stem evoked response (BERA) test is a worth test aiming evaluation of the degree of hearing deficit.

In a study published in 2011 by the American Academy of Pediatrics on "Long-term sequelae common among bacterial meningitis survivors"12, it was observed that $49.2 \%$ of the participants were having long-term sequelae (hearing loss accounted for $6.7 \%)$.

The rationale of my study is that this study is thought help us in knowing the frequency of hearing deficit and in turn, forming a preventive strategy to treat patients of meningitis earlier. This is thought to lessen the toll of hearing loss and long term educational and social difficulties these patients may experience. This study may also help in providing rehabilitation to the patients detected by this study in the form of hearing aids.

\section{MATERIAL \& METHODS}

The study was conducted after permission from ethical committee. A total of 151 patients admitted in Paediatric Medicine Department, Nishtar Hospital Multan, from October 2019 to March 2020 with bacterial meningitis, age more than 1 month to 12 years were included. Bacterial meningitis was defined as positive CSF in terms of white blood cell (WBC) more than 10/ ul in CSF. ${ }^{13}$ Children having meningomyelocele, past central nervous system pathology, seizure disorder, hydrocephalus, past history of recurrent meningitis or acute head trauma were not enrolled.

Informed consent was taken from the parents and risks \& benefits of the study were explained. Apart from the presenting complaints, necessary information like the age and gender were noted. Examination of the child was done to assess the condition of child. Treatment of child was started according to the standard protocol for bacterial meningitis. CSF examination of all the patients was sent to the same laboratory. BERA test was performed before discharge of the patient from the hospital. It was performed by same qualified audiologist in every patient on same apparatus to reduce bias in results. The outcome variable that is sensorineural hearing loss in bacterial meningitis was noted on specifically designed Performa.

All collected Data was entered in SPSS-10. The quantitative data like age was presented as mean and standard deviation. The qualitative data like gender, and sensorineural hearing loss (SNHL) was presented as frequency and percentages. Graphs and tables were used to represent data. The quantitative data like age was presented as mean and standard deviation. Effect modifiers were controlled by the stratification of data with regard to age and gender of the patient. Post stratification chi square test was applied taking $\mathrm{p}$ value less than $0.5 \%$ as significant.

\section{RESULTS}

There were 151 patients in total. Males were $83 / 151$ (55\%) while females were 68/151 (45\%). Mean age of the patients was $11.85+6.12$ months ranging from a minimum of 2 months to a maximum of 12 years. Hearing loss was found to be present in $26 / 151$ (17.2\%) while there was no hearing loss in 125/151 (82.8\%). Hearing loss was on the right side in 13/26 (50\%), left side in 10/26

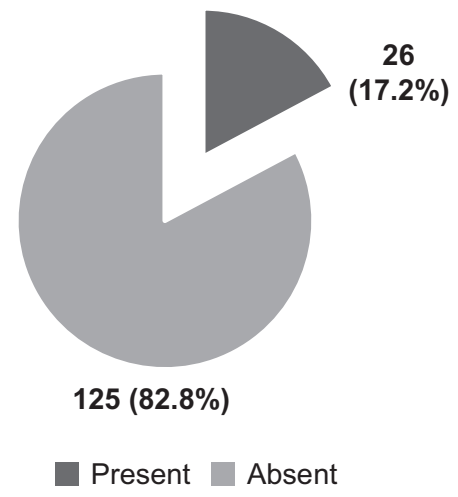

Figure-1. Frequency of hearing loss in the present study $(n=151)$

(38.46\%) and on both sides in 3/26 (11.54\%). 
Table-I shows that when the effect of gender was noted on hearing loss, it was found that among 83 males hearing loss was found to be present in 16/83 (19.28\%) while it was absent in $67 / 83(80.72 \%)$ patients. On the other hand among 58 females hearing loss was present in 10/68 (14.7\%) while it was absent in 58/68 $(85.29 \%)$ patients $(p$-value $=0.459)$. Table No.1 also shows that when the effect of age was noted on the frequency of hearing loss, it was found that among those children with age < 14 years there were 91 patients in total. Hearing loss was present in $17 / 91(18.68 \%)$ patients while it was absent in 74/91 (81.31\%). On the other hand among those with age $>14$ years there were 60 patients in total. Hearing loss was found to be present in 9/60 (15\%) while it was absent in 51/60 $(85 \%)$ patients ( $p$-value $=0.558)$.

\begin{tabular}{|l|l|c|c|c|}
\hline \multicolumn{2}{|c|}{ Characteristics } & \multicolumn{2}{c|}{ Hearing Loss } & $\begin{array}{c}\text { P. } \\
\text { Value }\end{array}$ \\
\cline { 2 - 5 } & Yes (n=26) & No (n=125) & (no \\
\hline \multirow{2}{*}{ Gender } & Female & $10(38.5 \%)$ & $58(46.4 \%)$ & 0.459 \\
\cline { 2 - 5 } & Male & $16(61.5 \%)$ & $67(53.6 \%)$ & \\
\hline \multirow{2}{*}{ Age } & $2-13$ months & $17(65.4 \%)$ & $74(59.2 \%)$ & \multirow{2}{*}{0.558} \\
\cline { 2 - 5 } & $>14$ months & $9(34.6 \%)$ & $51(40.8 \%)$ & \\
\hline
\end{tabular}

Table-I. Frequencies of hearing loss with respect to patients characteristics $(n=151)$

\section{DISCUSSION}

Bacterial meningitis is a serious condition attributed to high rates of mortality as well as disabling sequelae. ${ }^{14}$ Timely identification of patients having high risk of unwanted outcomes is essential for the prevention and appropriate treatment.

Comparable to various other researchers, male predominance was observed in the present study but without any significant relationship with the hearing loss. ${ }^{13,15}$

In the present study, hearing loss was found to be present in $26 / 151$ (17.2\%) while there was no hearing loss in 125/151 (82.8\%). Hearing loss was on the right side in $13 / 26(50 \%)$, left side in $10 / 26$ (38.46\%) and on both sides in 3/26 (11.54\%). In a local study from Lahore in $2018^{13}$, analyzing 175 children with meningitis, $22 \%$ of the children were found to have hearing loss. Another local study in $2008^{16}$ noted frequency of hearing loss to be $20 \%$ among children of BM. A study from Kenya ${ }^{17}$ reported high frequency of hearing loss as $43 \%$ among children having bacterial meningitis. Fortnum $\mathrm{H}$ and Davis $\mathrm{A}$ from $\mathrm{UK}^{18}$ in their 10 years retrospective analysis comprising data of more than 10 years among children having bacterial meningitis found survival among $88.4 \%$. it was also noted that $7.4 \%$ of the survivors undergoing audiological assessment were found to have some degree of hearing loss due to meningitis. Bacterial meningitis was also labeled to contribute to SNHL of any extent among children of any age. Another research from Neherlands ${ }^{19}$ noted $13 \%$ of the children with bacterial meningitis to have hearing loss. In developing countries, higher frequency of hearing loss among children having bacterial meningitis could be due to low rates of vaccination and complicated course of bacterial meningitis. Precise mechanism of hearing loss following bacterial meningitis is not known but insult to the cochlea as well as labyrinthine system is thought to be the underlying pathophysiology. ${ }^{20}$

Namani S et al noted most common neurological complication of bacterial meningitis among children to be subdural effusion, recurrent seizures and hydrocephalus. ${ }^{21}$ It was also seen that risk of neurological complications was more among infants. In the present study, we also noted that $60.2 \%$ of the children were aged less than14 months.

Deafness is known to be a frequent complication of the bacterial meningitis during childhood. Among developed countries, around $10 \%$ of the survivors of bacterial meningitis have permanent SNHL while many others are left with transient hearing loss. ${ }^{22}$ Both types of hearing impairments are known to develop in the $1^{\text {st }}$ few days of the disease. Audiological testing among children having bacterial meningitis needs to start as early as possible once the acute phase of the disease ends. It is also noticed by researchers that repeated testing need to be done among those children who are found to have hearing loss at the $1^{\text {st }}$ assessment. ${ }^{26}$ 
There were a number of limitations in our study including a smaller sample size due to limited facilities and time duration to complete the study. Also we need to see which organisms responsible for meningitis were more frequently associated with SNHL and what other factors can attribute to its causation. We also need to see the long term outcome of all the children with bacterial meningitis to see any slight residual effect while they reach school going age. There needs to be a larger, longer and better designed study to address the above mentioned shortcomings in our study.

\section{CONCLUSION}

$\mathrm{SNHL}$ is a frequently encountered complication in our population of children suffering with bacterial meningitis. SNHL should be sought early and promptly diagnosed in all the patients presenting with bacterial meningitis.

\section{ACKNOWLEDGEMENT}

The authors would like to thank Muhammad Aamir (Bahawalpur) for his assistance is statistical analysis.

Copyright@ 27 June, 2020.

\section{REFERENCES}

1. Hoffman O, Weber RJ. Pathophysiology and treatment of bacterial meningitis. Ther Adv Neurol Disord. 2009; 2(6):1-7.

2. Seth R, Murthy PSR, Sistla S, Subramanian M, Tamilarasu K. Rapid and accurate diagnosis of acute pyogenic meningitis due to streptococcus pneumoniae, haemophilusinfluenzae type $b$ and neisseria meningitidis using A Multiplex PCR Assay. J Clin Diagn Res. 2017; 11(9):FC01-4.

3. Kariyawasam AGTA, Fonseka CL, Singhapura SDAL, Hewavithana JS, Herath HMM, Pathirana KD. Bilateral hypoglossal nerve palsy due to brainstem infarction: A rare presentation of presumed pyogenic meningitis. Case Reports in Neurological Medicine. 2018; 2018:1-4.

4. Salih KE, Saeed NE, Karsani MS, Elshayeb AA, Ibrahim SA. Pattern of bacterial meningitis in Sudanese children, Omdurman, Sudan. African Journal of Microbiology Research 2010; 4(24):2670-73.
5. Rafeeda K, Paul B, Mathew L. Aetiology of acute pyogenic meningitis in children in a tertiary care hospital, Kerala. J Acad Clin Microbiol. 2018; 20(1):22.

6. Abdelrahim NA, Fadl-Elmula IM, Ali HM. Bacterial meningitis in Sudanese children; critical evaluation of the clinical decision using clinical prediction rules. BMC Pediatr 2019; 19:319.

7. Prober CG. Acute bacterial meningitis beyond neonatal period. In: Kliegman RM, Behrman RE, Jenson HB, Stanton BF. Nelson textbook of pediatrics Philadelphia: Saunders; 2011. 2087-88.

8. Higginson $\mathrm{CB}$, Martin $\mathrm{C}$, Cook A. Initial evaluation and management of bacterial meningitis in an emergent setting: A review. Advanced Emergency Nursing Journal. 2010; 32(4):301-13.

9. Yerramilli A, Mangapati $P$, Prabhakar S, Sirimulla $H$, Vanam S, Voora Y. A study on the clinical outcomes and management of meningitis at a tertiary care centre. Neurol India. 2017; 65(5):1006.

10. Fortnum HM. Hearing impairment after bacterial meningitis: A review. Archives of Disease in Childhood. 1992; 67(9):1128-1133.

11. Karanja BW, Oburra HO, Masinde P, Wamalwa D. Risk factors for hearing loss in children following bacterial meningitis in a Tertiary Referral Hospital. Int J Otolaryngol. 2013; 2013:354725.

12. Kemp C. Long-term sequelae common among bacterial meningitis survivors. AAP News 2011; $32(4): 2$.

13. Zeeshan F, Bari A, Dugal MN, Saeed F. Hearing impairment after acute bacterial meningitis in children. Pak J Med Sci. 2018; 34(3):655-9.

14. National Collaborating Centre for Women's and Children's Health (UK). Bacterial meningitis and meningococcal septicaemia: Management of bacterial meningitis and meningococcal septicaemia in children and young people younger than 16 years in primary and secondary care. London: RCOG Press; 2010. (NICE Clinical Guidelines, No. 102.) 7, Long-term management. Available from: https://www.ncbi.nlm.nih. gov/books/NBK83082/.

15. Jawaid A, Bano S, Haque A, Arif K. Frequency and outcome of meningitis in pediatric intensive care unit of Pakistan. Journal of College of Physicians and Surgons Pakistan. 2016;26(8):716.

16. Asghar RM, Ghani Z, Sharif M. Causative organisms, clinical course and complications of pyogenic meningitis in children. J Rawalpindi Med Coll. 2008; 12(2):88-91. 
17. Kutz JW, Simon LM, Chennupati SK, Giannoni CM, Manolidis S. Clinical predictors for hearing loss in children with bacterial meningitis. Arch Otolaryngol Neck Surg. 2006; 132(9):941-945.

18. Fortnum $H$, Davis $A$. Hearing impairment in children after bacterialmeningitis: Incidence and resource implications. Br J Audiol. 1993; 27(1):43-52.

19. Lucas MJ, Brouwer MC, van der Ende A, van de Beek D. Outcome in patients with bacterial meningitis presenting with a minimal Glasgow Coma Scalescore. Neurol Neuroimmunol neuroinflammation 2014; 1(1):e9.

20. Katijah KS, Emma RR. Paediatric meningitis and hearing loss in a developing country: Exploring the current protocols regarding audiological management following meningitis. Afr $\mathrm{J}$ Infect Dis. 2010; 4(2):51-60.
21. Namani SA, Koci BM, Milenković Z, Koci R, QehajaBuçaj E, Ajazaj L, et al. Early neurologic complications and long-term sequelae of childhood bacterial meningitis in a limited-resource country (Kosovo). Childs Nerv Syst. 2013 Feb; 29(2):275-80.

22. Wilson C, Roberts A, Stephens D. Improving hearing assessment of children post-meningitis. Arch Dis Child. 2003; 88(11):976-977.

23. Rodenburg-Vlot, MB, Ruytjens, L, Oostenbrink, R, van der Schroeff MP. Repeated audiometry after bacterial meningitis: consequences for future management. Otology \& Neurotology 2018; 39(5):e301-6.

\begin{tabular}{|c|l|l|c|}
\hline \multicolumn{3}{|c}{ AUTHORSHIP AND CONTRIBUTION DECLARATION } \\
\hline Sr. \# & \multicolumn{1}{|c|}{ Author(s) Full Name } & \multicolumn{1}{|c|}{ Contribution to the paper } & Author(s) Signature \\
\hline 1 & Rabia Saleem Safdar & Idea, Methodology, Drafting. & \\
\hline 2 & M Faisal Mehar & $\begin{array}{l}\text { Data analysis, Data } \\
\text { Interpretation. } \\
\text { Data collection, Literature } \\
\text { review. } \\
4\end{array}$ & $\begin{array}{l}\text { Madiha Naz } \\
\text { Literature review, Proof } \\
\text { reading. } \\
\text { Literature review, Discussion. }\end{array}$ \\
\hline 6 & Afsheen Asghar Khan & $\begin{array}{l}\text { Nusrat Buzdar } \\
\text { Data collection, Literature } \\
\text { review. }\end{array}$ \\
\hline
\end{tabular}

